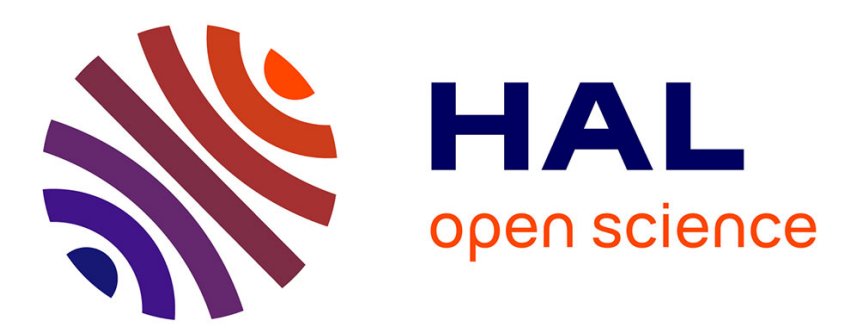

\title{
Biochemical and structural studies of target lectin SapL1 from the emerging opportunistic microfungus Scedosporium apiospermum
}

Dania Martínez-Alarcón, Viviane Balloy, Jean-Philippe Bouchara, Roland J Pieters, Annabelle Varrot

\section{To cite this version:}

Dania Martínez-Alarcón, Viviane Balloy, Jean-Philippe Bouchara, Roland J Pieters, Annabelle Varrot. Biochemical and structural studies of target lectin SapL1 from the emerging opportunistic microfungus Scedosporium apiospermum. Scientific Reports, 2021, 11, pp.16109. 10.1038/s41598-021-95008-4 . hal-03320727

\section{HAL Id: hal-03320727 https://hal.science/hal-03320727}

Submitted on 16 Aug 2021

HAL is a multi-disciplinary open access archive for the deposit and dissemination of scientific research documents, whether they are published or not. The documents may come from teaching and research institutions in France or abroad, or from public or private research centers.
L'archive ouverte pluridisciplinaire HAL, est destinée au dépôt et à la diffusion de documents scientifiques de niveau recherche, publiés ou non, émanant des établissements d'enseignement et de recherche français ou étrangers, des laboratoires publics ou privés. 


\section{scientific reports}

Check for updates

\section{OPEN Biochemical and structural studies of target lectin SapL1 from the emerging opportunistic microfungus Scedosporium apiospermum}

Dania Martínez-Alarcón ${ }^{1,2}$, Viviane Balloy ${ }^{3}$, Jean-Philippe Bouchara ${ }^{4}$, Roland J. Pieters ${ }^{2} \&$ Annabelle Varrot ${ }^{1 凶}$

Scedosporium apiospermum is an emerging opportunistic fungal pathogen responsible for lifethreatening infections in humans. Host-pathogen interactions often implicate lectins that have become therapeutic targets for the development of carbohydrate mimics for antiadhesive therapy. Here, we present the first report on the identification and characterization of a lectin from S. apiospermum named SapL1. SapL1 was found using bioinformatics as a homolog to the conidial surface lectin FleA from Aspergillus fumigatus known to play a role in the adhesion to host glycoconjugates present in human lung epithelium. In our strategy to obtain recombinant SapL1, we discovered the importance of osmolytes to achieve its expression in soluble form in bacteria. Analysis of glycan arrays indicates specificity for fucosylated oligosaccharides as expected. Submicromolar affinity was measured for fucose using isothermal titration calorimetry. We solved SapL1 crystal structure in complex with $\alpha$-methyl-L-fucoside and analyzed its structural basis for fucose binding. We finally demonstrated that SapL1 binds to bronchial epithelial cells in a fucose-dependent manner. The information gathered here will contribute to the design and development of glycodrugs targeting SapL1.

During the last decades, an increased incidence of invasive infections, especially in immunosuppressed patients, has been caused by previously rare fungal pathogens such as species from the Scedosporium genus ${ }^{1,2}$. This genus comprises more than ten worldwide distributed soil saprophyte species whose taxonomy has been previously described based on molecular phylogenetic ${ }^{3,4}$. Scedosporium species may lead to bronchitis and allergic bronchopulmonary mycoses as well as severe disseminated infections through inhalation of conidia. They rank second among the filamentous fungi colonizing the respiratory tract of cystic fibrosis (CF) patients, after Aspergillus fumigatus $^{4}$. Together with S. boydii and S. aurantiacum, S. apiospermum is the most common Scedosporium species able to chronically colonize the lungs of CF patients ${ }^{4,5}$. Because of their propensity to disseminate in case of immune deficiency, this fungal colonization of the airways is considered in some centers as a contraindication to lung transplantation that is the ultimate treatment in $\mathrm{CF}^{6}$. Besides, infections by Scedosporium species have also been reported in immunocompetent patients ${ }^{7}$.

The treatment of Scedosporium infections is challenging because its efficacy depends on the biological diagnosis which is a time-consuming process. The common co-colonization by other fungi or bacteria may lead to false negative results, especially from respiratory secretions of patients with $\mathrm{CF}^{4}$. Furthermore, Scedosporium species display a primary resistance to most current antifungals such as amphotericin B or first-generation triazole drugs as fluconazole or itraconazole and exhibit a limited susceptibility to the newest generations of antifungal drugs, i.e. echinocandins and voriconazole $e^{4,8}$. Nowadays, the first-line treatment involves combination therapy but following common recurrences and even without interruption of treatment, the recovery rates

${ }^{1}$ Univ. Grenoble Alpes, CNRS, CERMAV, 38000 Grenoble, France. ${ }^{2}$ Utrecht University, 3584 CG Utrecht, The Netherlands. ${ }^{3}$ Sorbonne Université, Inserm, Centre de Recherche Saint-Antoine, F-75012 Paris, France. ${ }^{4}$ UNIV Angers, Université de Bretagne Occidentale, SFR ICAT, CHU, Host-Pathogen Interaction Study Group (GEIHP, EA 3142), Institut de Biologie en Santé-IRIS, Angers, France. ${ }^{\square}$ email: annabelle.varrot@cermav.cnrs.fr 
are poor and mortality remains over $65 \%$ while it is almost $100 \%$ when dissemination occurs, reason why it has aroused special interest ${ }^{8-10}$.

Scedosporium infections begin with conidial adherence to tissues, followed by germination and hyphal elongation $^{11}$. The adherence allows it to avoid cleansing mechanisms aimed to eradicate the invading pathogens and represents the initial step towards infection ${ }^{11-14}$. Conidial adhesion is mediated by cell surface molecules (CSM), including carbohydrates where some of the most important described to date for Scedosporium species include peptidorhamnomannans (PRMs) ${ }^{15-17}$, a-glucans ${ }^{18}$, melanin ${ }^{19}$, ceramide monohexosides ${ }^{17,20}$, $\mathrm{N}$-acetyl$\mathrm{D}$-glucosamine-containing molecules ${ }^{21}$ and mannose/glucose-rich glycoconjugates ${ }^{17}$. Their presence and/or abundance on the cell surface vary according to the stage of development and is of great relevance to understand fungal pathobiology ${ }^{17}$. The carbohydrate binding proteins known as lectins also act as CSMs and were shown to have an essential role during pathogenesis in the host recognition and adhesion process ${ }^{22}$. They became drug targets for the development of carbohydrates related molecules as antiadhesives drugs ${ }^{12-14,23-26}$. The antiadhesive therapy approach is particularly promising since it does not kill the pathogen nor arrest its cell cycle. Consequently, resistance frequencies are very $l_{0} w^{13,23}$ and expected side effects in non-target tissues are lower than those caused by conventional antifungal compounds. This may allow its implementation as a prophylactic therapy for immunocompromised patients ${ }^{14}$.

Due to the emerging character of S. apiospermum, there is very limited information on its mechanisms of recognition and anchoring to the host. Furthermore, lectins from this microorganism have not been characterized to date, which hinders the development of an anti-adhesive therapy. Conversely, other filamentous fungal pathogens were investigated leading to the identification and characterization of their host binding modes. For example, in A. fumigatus, which is a saprophytic mold also responsible for bronchopulmonary infections in receptive hosts, the lectin FleA (or AFL) was identified and revealed to play a role in host-pathogen interactions ${ }^{27}$. FleA is a sixbladed $\beta$-propeller homodimer located on the conidial surface that recognizes human blood group antigens and mediates $A$. fumigatus binding to airway mucins and macrophages glycoproteins in a fucose-dependent manner ${ }^{28}$. In healthy individuals, this anchorage is critical for the mucociliary clearance process and the macrophagy; in fact, it has been described that fleA-deficient $(\triangle$ fleA) conidia are even more pathogenic than wild type (WT) conidia, both in healthy and chemically immunocompromised mice ${ }^{28,29}$. However, CF patients represent a very particular scenario because the mucus in their lungs is thicker, in relation with mucin overproduction and its high content in calcium ions, which modulates the supramolecular organization of mucin MUC5B by protein crosslinking ${ }^{29,30}$. This contributes to the suboptimal transport properties of mucus and compromises the pathogen clearance mechanisms ${ }^{29}$. Furthermore, the aberrant glycosylation in CF patients causes, among other things, an increase in the abundance of sialyl-Lewis $\mathrm{X}$ and Lewis $\mathrm{X}$ determinants in lung mucins ${ }^{31,32}$, which is translated as an increase in the fucose content. Therefore, in this context, the FleA (and homologous proteins) anchoring to the mucus layer plays an essential role in the colonization of the CF lungs by A. fumigatus.

Here, we have used the recently sequenced genome of $S$. apiospermum ${ }^{33}$ to identify a putative homologue of FleA that we have called SapL1 for Scedosporium apiospermum Lectin 1. The present report comprises SapL1 identification, its expression in soluble form in bacteria, an analysis of the fine specificity and affinity of the recombinant protein, as well as its structural characterization by X-ray crystallography and fucose-dependent binding to bronchial epithelial cells by fluorescence microscopy.

\section{Results}

Production and purification of SapL1. The hypothetical protein XP_016640003.1 (EMBL accession number), encoded by SAPIO_CDS9261 and from now on referred as SapL1, was identified through data mining using the FleA (pdb entry $4 \mathrm{D} 4 \mathrm{U}^{34}$ ) sequence as bait into the genome of the reference strain S. apiospermum IHEM $14462^{33}$. During the sequence analysis, we found that the first 74 amino acids of the putative protein (Uniprot A0A084FYP2) represent a very disordered region that is not present in any other related protein. We suspected that this peptide could be due to an error during the genome annotation. To verify it, we tried to get the gene from total mRNAs extracted from mycelium by 5' Rapid Amplification of cDNA Ends (5' RACE) using the following primers GSP1-SapL1 5'-TTAAGCAGGGGGCAGAACAGC-3' and GSP2-SapL1 5'-CCA ACGACCCAGCCAGAGTTCC-3' but we were unsuccessful. This could be due to the fact that the gene was not expressed in the conditions tested. We did not have access to total mRNAs from other morphological stages of the microfungus. Thus, we decided to focus on the identified carbohydrate recognition domain (CRD) of SapL1 starting from methionine-75 (Fig. S1). The SapL1 coding sequence (75-369) was fused to an N-terminal 6xHis tag cleavable by the Tobacco Etch virus protease (TEV) under regulation of $\operatorname{trc}$ and $T 7$ promoters into pProNde and pET-TEV vectors, respectively (Fig. 1A). Expression was performed in Escherichia coli and purification was carried out using immobilized metal affinity chromatography (IMAC). Unfortunately, the original expression yield with both vectors $\left(\sim 0.35 \mathrm{mg} \cdot \mathrm{L}^{-1}\right.$ of culture $)$ was too low to proceed with characterization studies. Therefore, we explored new alternatives to enhance the expression. First, the thioredoxin protein (Trx) as well as 6-His tag and TEV cleavage site were fused at the N-terminus of SapL1 by subcloning into the pET32-TEV vector (Fig. 1A). This strategy substantially increased the SapL1 production yield but most of the protein remained insoluble as part of inclusion bodies (Fig. S2).

A wide range of expression conditions were subsequently assayed to achieve sufficient soluble expression by modification of various parameters such as growth temperature, host strain, inducer concentration, optical density of the culture at induction, culture duration, etc. Sixty-nine different sets of parameters were assayed (Table S1) and it was possible to improve the yield up to $4 \mathrm{mg} \cdot \mathrm{L}^{-1}$ (Fig. 1B). The best set of conditions for SapL1 expression was using E. coli strain TRX, pProNde vector, LB medium, growth at $37^{\circ} \mathrm{C}$ and $160 \mathrm{rpm}$ until $\mathrm{OD}_{600}=0.4$, before a switch of the temperature to $16^{\circ} \mathrm{C}$ and overnight induction at OD 0.8 with $0.05 \mathrm{mM}$ IPTG and $1 \%$ L-rhamnose $(\mathrm{Rh})$. 
A)

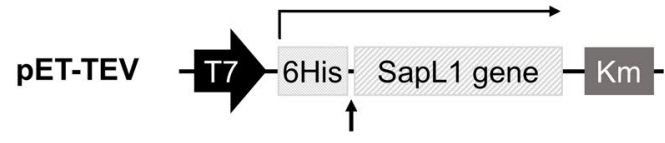

pPro-Nde - Trc $-\frac{\text { - }}{\uparrow \text { His }- \text { SapL1 gene }}-$ Amp-

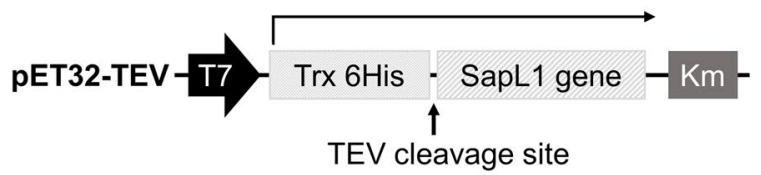

B)

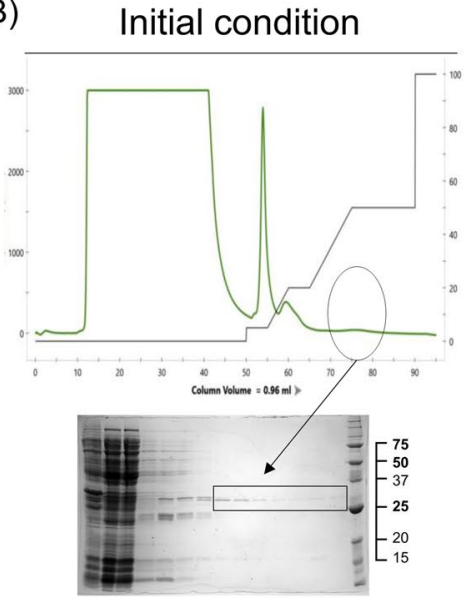

Improved condition

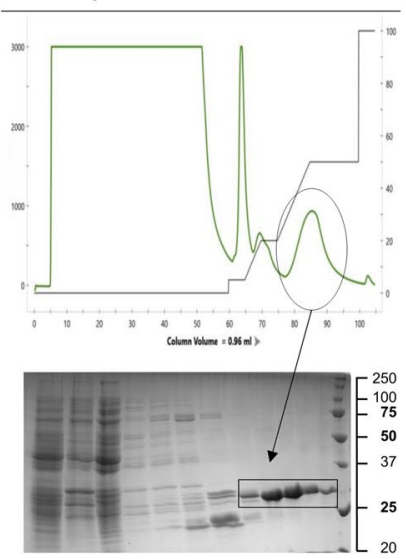

Figure 1. SapL1 production. (A) Schematic representation of the genetic constructs used for the expression of SapL1. (B) Representative chromatograms of SapL1 purification before and after the process with their respective profile on 15\% SDS-polyacrylamide gels (insoluble fraction, soluble fraction, flow through, washing and elution and molecular weight marker, from left to right respectively). The fractions containing SapL1 are delimited.

Rhamnose influence on SapL1 solubility. Interestingly, during the optimization of the expression conditions, we found that rhamnose (Rh) plays an essential role in the solubility and stability of SapL1. Therefore, we performed a new set of experiments to demonstrate the correlation between the amount of protein recovered after purification and the Rh concentration in the media. For this, we investigated SapL1 expression under the previously described conditions modified by supplementation of the culture medium with different concentrations of $\mathrm{Rh}(0.1 \%, 0.15 \%, 0.2 \%, 0.5 \%$ and $1 \%)$. Purification parameters were set to obtain high purity product and kept identical for all experiments. Figure 2 shows the chromatograms obtained for representative concentrations accompanied by their respective SDS-PAGE profile. To quantify SapL1 expression in these experiments, we integrated the area under peaks corresponding to the protein (Fig. 2, black bars). Thus, we confirmed that SapL1 recovery is directly proportional to the $\mathrm{Rh}$ concentration in the culture medium. Then, the experiment was repeated at three different concentrations $(0.1 \%, 0.15 \%, 0.2 \%)$ using $20^{\circ} \mathrm{C}$ as the induction temperature, and production behavior was similar to that found at $16^{\circ} \mathrm{C}$, but with lower performance.

Additional experiments also showed that SapL1 expression can be induced at high concentration of rhamnose in a dose-dependent manner, even without addition of IPTG when the pProNde vector is used (data not shown).

Biochemical characterization. We assayed the thermal stability of SapL1 in 26 different buffers in a pH range of 5 to 10 through Thermal Shift Assay (TSA). The most suitable condition for this protein was MES buffer $100 \mathrm{mM} \mathrm{pH} \mathrm{6.5,} \mathrm{where} \mathrm{a} \mathrm{single} \mathrm{denaturing} \mathrm{event} \mathrm{at} \mathrm{T}_{\mathrm{m}}$ of $55^{\circ} \mathrm{C}$ was observed (Fig. S3). Then, to estimate the molecular size and oligomerization state of the native protein, we performed size exclusion chromatography using an ENrich ${ }^{\text {Tx }}$ SEC 70 column (Bio-Rad) and 20 mM MES, $100 \mathrm{mM} \mathrm{NaCl}$, pH 6.5 as mobile phase. However, the protein displayed strong non-specific interactions with the matrix of the column and SapL1 could not be eluted even using $5 \mathrm{M}$ of $\mathrm{NaCl}$. Interestingly, it could be recovered when the buffer was supplemented with $20 \mathrm{mM}$ a-methyl fucoside or L-rhamnose, evidencing similar effects on SapL1 elution for both sugars. Due to the impossibility to estimate the molecular weight of SapL1 by size exclusion chromatography on this resin, we performed measurements in solution using Dynamic Light Scattering (DLS). We obtained a monodisperse peak corresponding to a protein of $72 \pm 29.4 \mathrm{kDa}$ corroborating that SapL1 forms dimers as FleA and other proteins of this family (monomer MW: $40 \mathrm{kDa}$, data not shown) ${ }^{27}$. The range of the standard deviation also suggested an ellipsoidal shape, which is characteristic for the dimers in this lectin family ${ }^{27,35}$.

Carbohydrate binding properties. A hemagglutination assay showed that recombinant SapL1 agglutinated rabbit red blood cells at $0.97 \mu \mathrm{g} \cdot \mathrm{mL}^{-1}$ (Fig. $3 \mathrm{~A}$ ). It confirms that the recombinant lectin is active and that its heterologous production in E. coli did not alter its hemagglutinating properties.

To identify the potential ligands of SapL1 on epithelial cell surfaces, we submitted SapL1 to the glycan array version 5.4 of the Consortium for Functional Glycomics (USA) consisting of 585 mammalian glycans. It was labelled with Fluorescein Isothiocyanate (FITC) in a molar ratio of 0.426 and its binding properties were analysed at two different concentrations ( 5 and $50 \mu \mathrm{g} \cdot \mathrm{mL}^{-1}$ ). As expected from its homology with FleA, SapL1 recognizes fucosylated oligosaccharides independently of the fucose linkage. The $\alpha 1,2$ and $\alpha 1,3 / 4$ linked fucosides displayed the highest affinity whilst the lowest was seen with the $\alpha 1,6$ linked ones. The weakest interactions with fucosylated compounds were reported for branched oligosaccharides (Figs. 3C and S4).

The affinity of SapL1 for L-fucose and $\alpha$-methyl-fucoside was determined by Isothermal Titration Calorimetry (ITC) and the $\mathrm{K}_{\mathrm{d}}$ was found to be $225 \pm 1.52 \mu \mathrm{M}$ and $190 \pm 1.44 \mu \mathrm{M}$, respectively with stoichiometry fixed to 1 since the measurements were done in the presence of an excess of ligand (Fig. 3B). These values are in agreement 

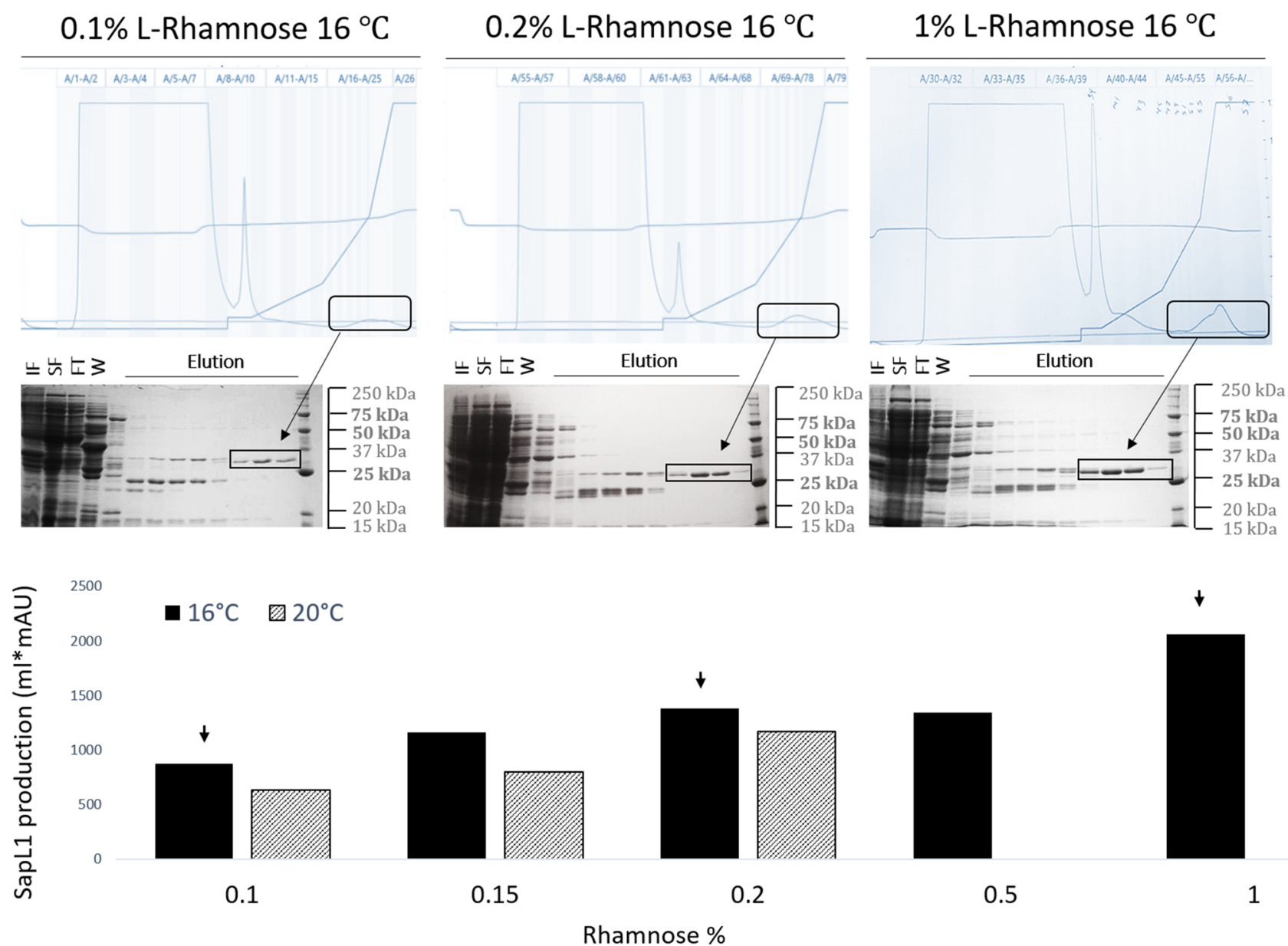

Rhamnose \%

Figure 2. Rhamnose influence on SapL1 solubility. (A) SapL1 purification chromatograms at $0.1 \%, 0.2 \%$, and $1 \%$ rhamnose with their corresponding SDS-PAGE profile. IF: Insoluble fraction, SF: Soluble fraction, FT: Flow through, W: wash and elution, from left to right respectively. Black rectangles indicate the elution peaks and elution fractions containing SapL1 on SDS-polyacrylamide gels. (B) Numerical values derived from the integration of areas under the peaks corresponding to SapL1 for each experiment. Black and striped bars represent the results for experiments performed at $16^{\circ} \mathrm{C}$ and $20^{\circ} \mathrm{C}$, respectively.

with the affinity constant (around $110 \mu \mathrm{M}$ ) reported for FleA for $\alpha$-methyl-fucoside ${ }^{36}$. No binding interaction was observed for SapL1 with rhamnose by ITC (data not shown).

Analysis of the glycans constituting blood group determinants revealed that SapL1 binds to all epitopes with a preference for $\mathrm{H}$ type 2 blood group (Fuca1-2Gal $\beta 1-4 \mathrm{GlcNAc} \beta$ ) then Lewis a (Gal $\beta 1-3$ (Fuca1-4)GlcNAc $\beta$ ) and Lewis X (Gal $\beta 1-4$ (Fuca1-3)GlcNAc $\beta$ ). However, most of the recognized branched oligosaccharides contained the core fucose Fuca1-6. Epitopes with two fucose units, such as Lewis b and fucosylated polylactosamine, were also well recognized. Addition of a galactose or a GalNAc as in blood group B or A antigens did not impair Fucal-2 recognition (Fig. 3C). Spacers used to join the carbohydrates to the chip also display a strong influence on binding. It is remarkable that $70 \%$ of the 90 positive binders contained either the spacer Sp0 $\left(\mathrm{CH}_{2} \mathrm{CH}_{2} \mathrm{NH}_{2}\right)$ or Sp8 $\left(\mathrm{CH}_{2} \mathrm{CH}_{2} \mathrm{CH}_{2} \mathrm{NH}_{2}\right)$. Those spacers also display a strong influence on binding, especially for small glycans such as Gala1-3(Fuca1-2)Gal $\beta 1-4$ (Fuca1-3)GlcNAc $\beta$ which was recognized when attached to Sp0 but not to Sp8. This may be due to a steric hindrance caused by the modification of carbohydrate presentation on the surface of the chip.

Overall structure of SapL1. SapL1 was co-crystallized with $\alpha$-methyl-fucoside and the structure of the complex was solved by molecular replacement at $2.3 \AA$ resolution in the $\mathrm{P} 2{ }_{1}$ space group using the coordinates of FleA ( $\mathrm{PDB}$ code $4 \mathrm{D} 4 \mathrm{U}^{34}$ ) as the search model. The asymmetric unit contained two monomers, assembled as a dimer with all 295 amino acids visible apart of the $\mathrm{N}$-terminal methionine. See data collection and refinement statistics in Table 1. SapL1 folds into the canonical six-bladed $\beta$-propeller with six-binding sites at the interface between blades typical for this family of lectin (Fig. 4). A fucose moiety was found in 5 and 4 of the six binding pockets of chains A and B, respectively while glycerol originating from the crystallizing solution was found in the other binding sites.

The overall fold of SapL1 and FleA as well as the overall dimer are very similar with a rsmd of 1.2 and $1.26 \AA$, respectively. They share $43 \%$ of sequence identity and both proteins present almost the same distribution of $\beta$-strands except for an extra strabd in blade $2(\beta 10)$, the lack of the last strand of blade 4 in SapL1, and the 
A)

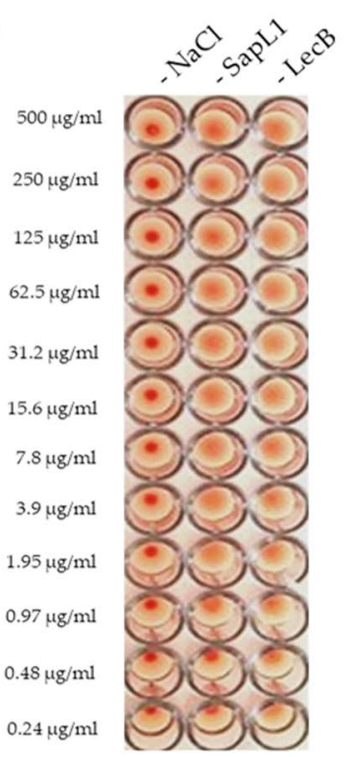

B)

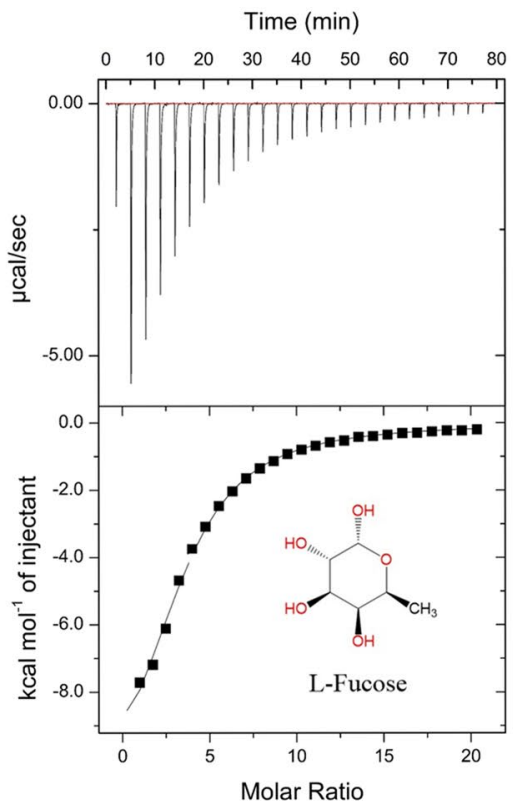

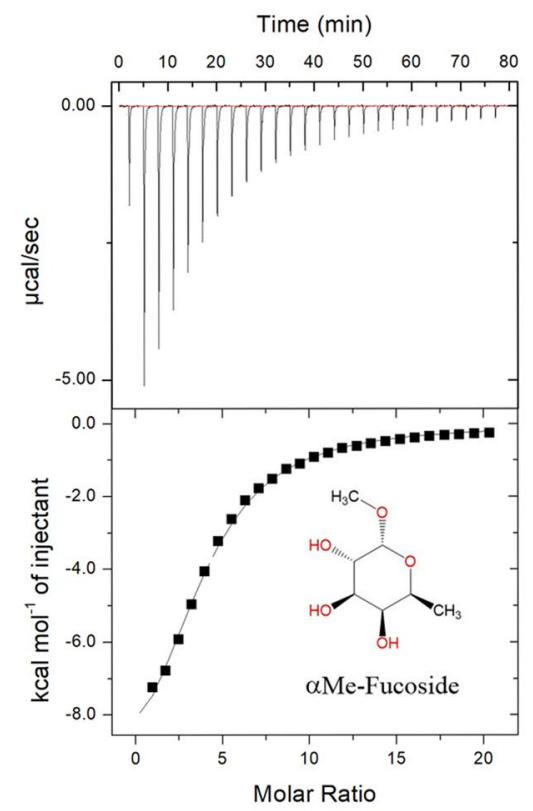

C)
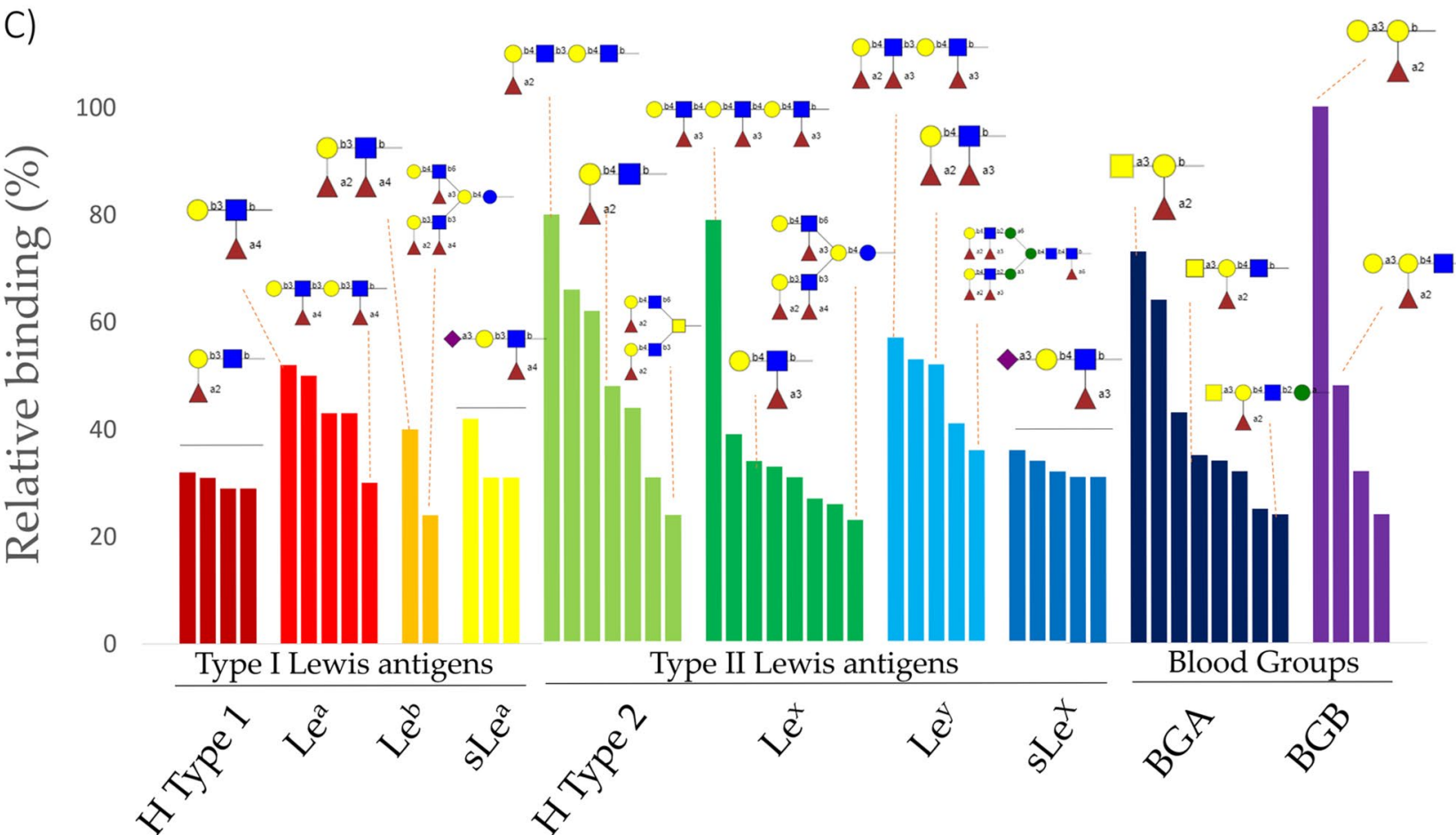

Type II Lewis antigens
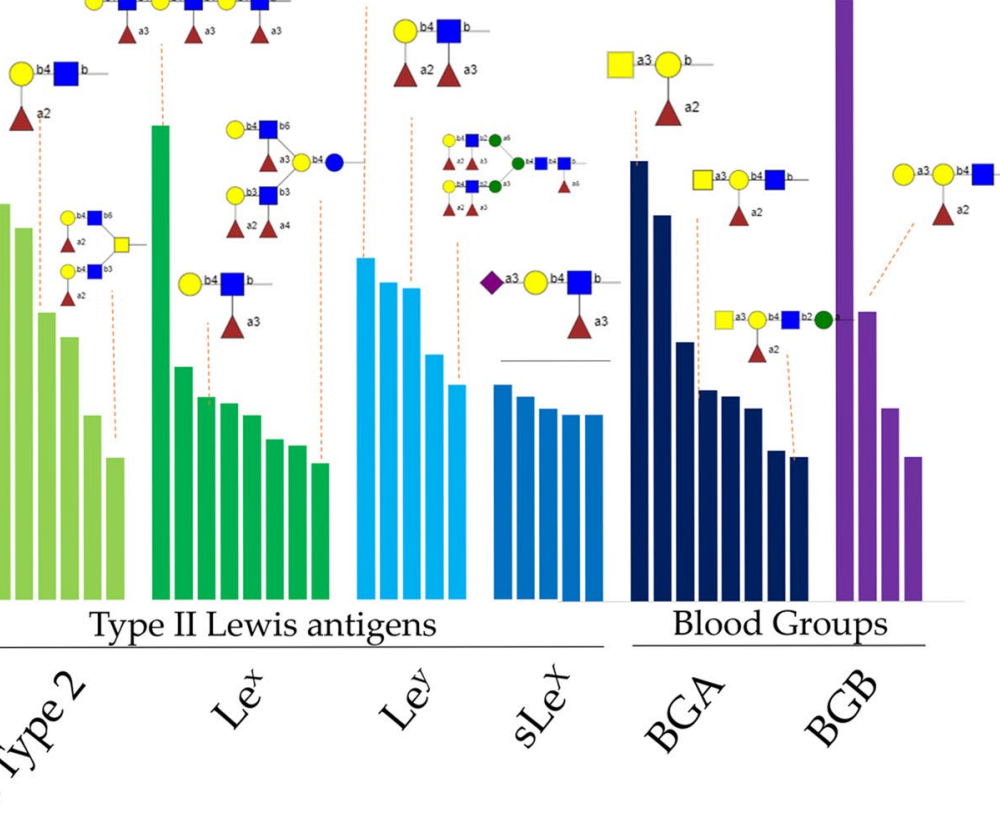

Blood Groups
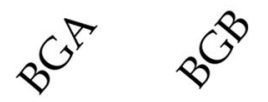
$\triangle$ Fuc
Gal
Glc
Man
GlcNAc
GalNAc
Neu5Ac

Figure 3. SapL1 carbohydrate binding properties. (A) Hemagglutination assay of SapL1 on fresh rabbit erythrocytes. Negative and positive controls consist of $150 \mathrm{mM} \mathrm{NaCl}$ and the lectin LecB from Pseudomonas aeruginosa, respectively. (B) Titration of SapL1 with L-fucose and $\alpha$-methyl-fucoside with the thermogram and the integration displayed at the top and bottom, respectively. (C) Analysis of the interactions of SapL1 with blood group epitopes. The graph shows the relative binding of SapL1 to glycans containing Lewis and ABH blood group antigens from the 90 hits identified as binders. 


\begin{tabular}{|c|c|c|}
\hline \multicolumn{3}{|l|}{ Data collection } \\
\hline Beamline & \multicolumn{2}{|c|}{ SOLEIL Proxima 1} \\
\hline Wavelength $\left(\mathrm{A}^{\circ}\right)$ & \multicolumn{2}{|c|}{0.97857} \\
\hline Space group & \multicolumn{2}{|l|}{$\mathrm{P} 2_{1}$} \\
\hline Unit cell dimensions a, b, c $(\AA), \alpha, \beta, \gamma\left(^{\circ}\right)$ & \multicolumn{2}{|c|}{$76.06,45.66,83.48,90,105.05,90$} \\
\hline No. of monomers in ASU & \multicolumn{2}{|c|}{2} \\
\hline Resolution $(\AA)$ & \multicolumn{2}{|c|}{$40.0-2.4(2.46-2.4)$} \\
\hline Rmerge & \multicolumn{2}{|c|}{$0.085(0.428)$} \\
\hline Rpim & \multicolumn{2}{|c|}{$0.07(0.356)$} \\
\hline Mean $I / \sigma(I)$ & \multicolumn{2}{|c|}{$5.3(1.6)$} \\
\hline Completeness (\%) & \multicolumn{2}{|l|}{$98.2(98.4)$} \\
\hline Multiplicity & \multicolumn{2}{|l|}{$2.7(2.7)$} \\
\hline $\mathrm{CC} 1 / 2$ & \multicolumn{2}{|c|}{$0.991(0.7)$} \\
\hline No. reflections /No. Unique reflections & \multicolumn{2}{|c|}{$58305 / 21570$} \\
\hline \multicolumn{3}{|l|}{ Refinement } \\
\hline Resolution $(\AA)$ & \multicolumn{2}{|l|}{$40.0-2.4$} \\
\hline No. of reflections in working set / Free set & \multicolumn{2}{|c|}{$21561 / 1089$} \\
\hline$R$ work/ $R$ free & \multicolumn{2}{|c|}{$17.5 / 24.0$} \\
\hline R.m.s Bond lengths $(\AA)$ & \multicolumn{2}{|l|}{0.017} \\
\hline Rmsd Bond angles $\left(^{\circ}\right)$ & \multicolumn{2}{|l|}{1.94} \\
\hline Rmsd Chiral $\left(\AA^{3}\right)$ & \multicolumn{2}{|l|}{0.087} \\
\hline No. atoms / Bfac $\left(\AA^{2}\right)$ & Chain A & Chain B \\
\hline Protein & $2222 / 32.6$ & $2220 / 40.8$ \\
\hline Ligand and heterogen & $89 / 31.6$ & $66 / 36.9$ \\
\hline Waters & $111 / 31.0$ & $69 / 33.2$ \\
\hline Ramachandran Allowed / Favored/ Outliers (\%) & $96 / 4 / 0$ & $95 / 4 / 1$ \\
\hline PDB Code & \multicolumn{2}{|l|}{ 6TRV } \\
\hline
\end{tabular}

Table 1. Data-collection and refinement statistics ${ }^{\star}$ Values in parentheses are for the outer shell.
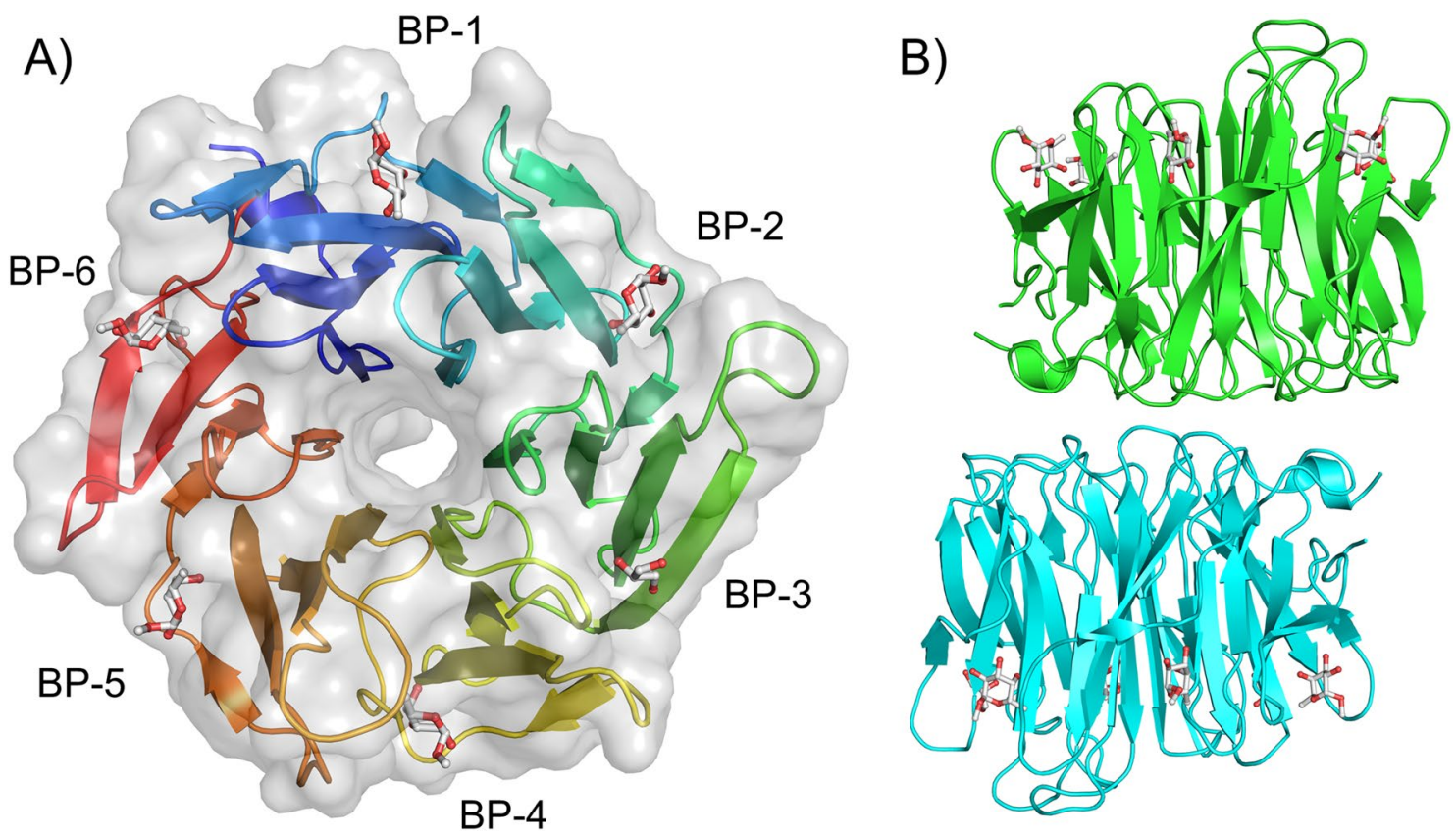

Figure 4. SapL1 overall structure. (A) Surface and cartoon representation of SapL1 monomer colored from blue ( $N$-terminal end) to red (C-terminal end). BP: Binding pockets. (B) Representation of SapL1 dimer colored by monomer with ligand depicted in sticks. 

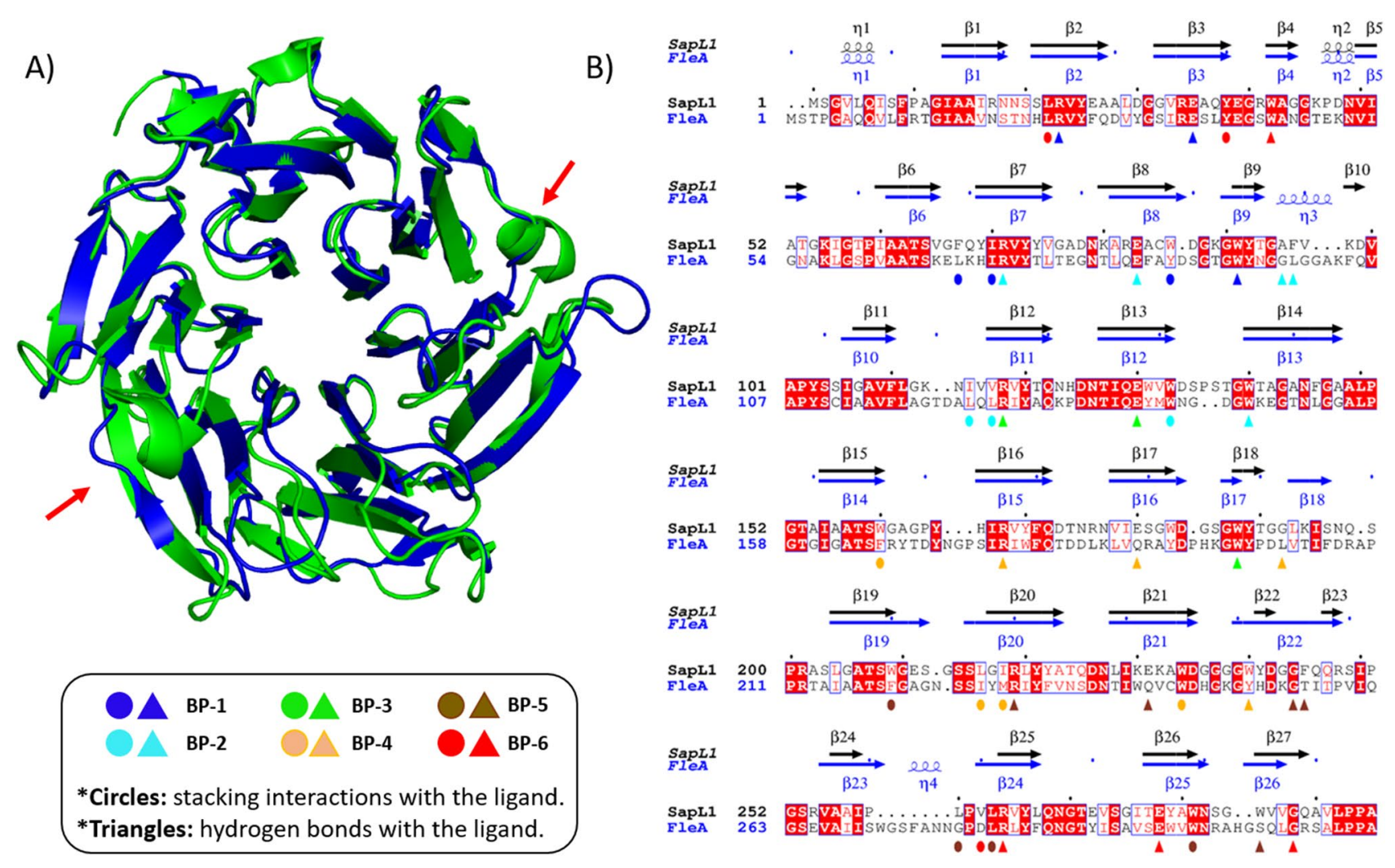

Figure 5. SapL1/FleA comparison. (A) Overlay of SapL1 (blue, PDB: 6TRV) and FleA (green, PDB: 4D4U) structures. Red arrows indicate the main differences between structures. (B) Sequence alignment of SapL1 and FleA with display of their secondary structure elements. The residues involved in ligand interactions of each pocket are indicated by circles for hydrophobic and stacking interactions and by triangles for hydrogen bonds colored according to the binding pocket: BP-1, blue; BP-2 cyan; BP-3 green; BP-4, orange, BP-5, brown; BP-6, red.

external face of blade 5 , in which FleA displays an elongated $\beta$-strand $(\beta 22)$ that is split in two in SapL1 $(\beta 22 / 23)$. It is remarkable that the structure of the first 3 blades is highly conserved in both proteins, while the second half (blades 3-6) displays the largest discrepancies. Furthermore, FleA also presents two additional small $\alpha$-helices ( $\dot{\eta} 3$ and $\eta \dot{4})$, located in the loops between sheets that serve as connectors for blades $(2 / 3$ and 5/6, respectively, Fig. 5). Similar conclusions can be drawn when comparing SapL1 to its homologue AOL in Aspergillus oryzae ${ }^{37}$.

Protein-ligand interactions. Due to divergence in the tandem repeat sequence forming each blade of the propeller, the six binding sites of SapL1 monomer are not equivalent, but they share important conserved features. Hydrophobic interactions are observed between the C6 of the fucose and at least three residues of the protein (mainly isoleucine, tryptophan/tyrosine and leucine). The $\mathrm{O} 2$ and $\mathrm{O} 3$ hydroxyls make strong hydrogen bonds with a conserved triad of amino acids consisting of an arginine, a glutamic acid and a tryptophan. In the cases where glycerol was found in the binding pocket, its own hydroxyls mimic the interactions of fucose with these same residues (Fig. 6). It is to be noted that SapL1 binding sites are more conserved than FleA binding sites where a glutamine can replace the glutamic acid and a tyrosine the tryptophan in the triad (Fig. S5).

The $\mathrm{O} 2$ hydroxyl seemed to be the most versatile position, since it established interactions with an adjacent loop only present in four of the six binding sites (BPs 2, 4, 5 and 6). This is particularly interesting since the binding pockets that do not contain this loop (BPs 1 and 3) were mostly occupied by glycerol instead of fucose, indicating that those interactions could be responsible for enhancing the affinity and should be explored for development of inhibitors.

Binding to epithelial cells. In order to investigate the role of SapL1 in host-pathogen interactions and especially in adhesion, fluorescence microscopy was used. FITC-labelled SapL1 was incubated at two different concentrations with BEAS-2B human bronchial epithelial cells. The microscopy images, obtained for two separate experiments, clearly show binding of the lectin to those cells (Fig. 7). Fluorescence was observed all around the cell surface but also concentrated in some part of the nucleus. A strong fluorescence signal was already observed at the lowest concentration used $\left(5 \mu \mathrm{g} \mathrm{mL}^{-1}\right)$. The binding of SapL1 was inhibited in the presence of its cognate ligand: $\alpha$-methyl-fucoside (Fig. 7E-G). Some background signal was still observed in the first experiment (Fig. 7E, G) whilst it was totally abolished in the duplicate (Fig. 7F, H). These data show that SapL1 binding to the cells is dependent on the recognition of fucosylated carbohydrates. 

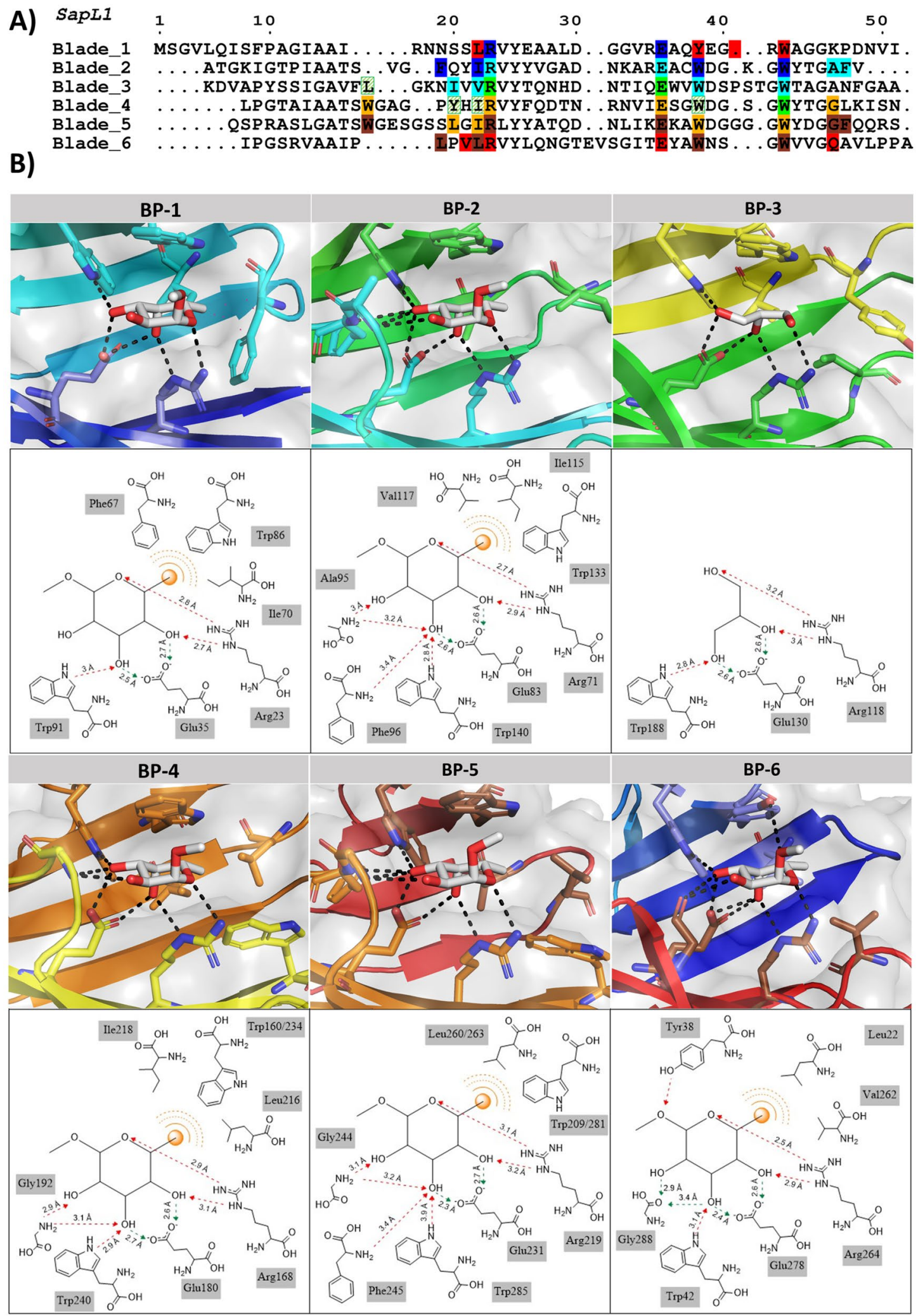

Figure 6. SapL1-ligand interactions. (A) The sequence alignment of the 6 blades of SapL1. The residues involved in ligand binding interactions are indicated in solid boxes: BP-1, blue; BP-2 cyan; BP-3 green; BP-4, orange, BP-5, brown; BP-6, red. Striped green boxes indicate the four additional residues expected to be involved in fucose binding within BP-3 that were not visible in the structure since only glycerol was attached to this pocket. (B) Zoom on the interactions of ligand with each binding site of SapL1 and their schematic representation. 
SapL1-FITC (5 $\left.\mu \mathrm{g} \mathrm{mL}^{-1}\right)$
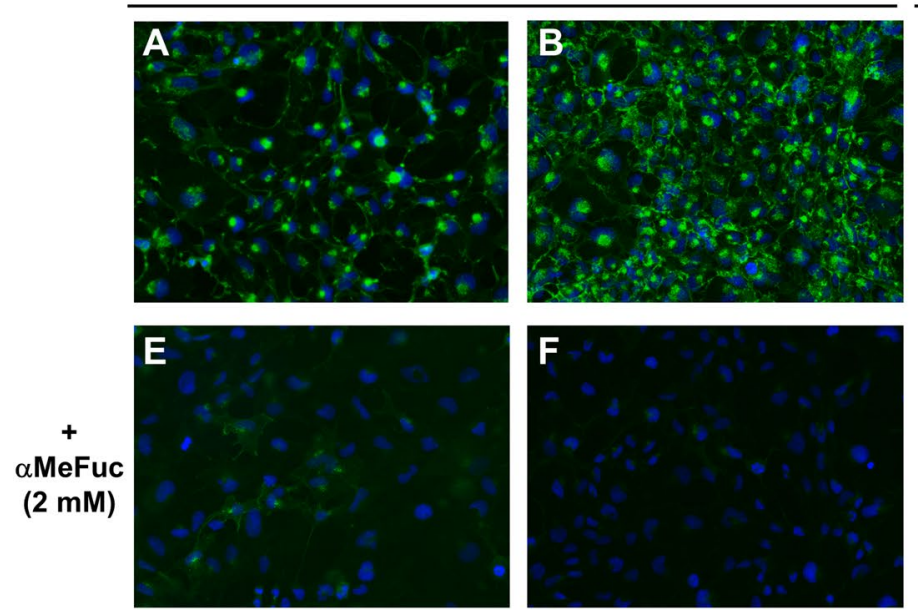

SapL1-FITC $\left(10 \mu g \mathrm{~mL}^{-1}\right)$
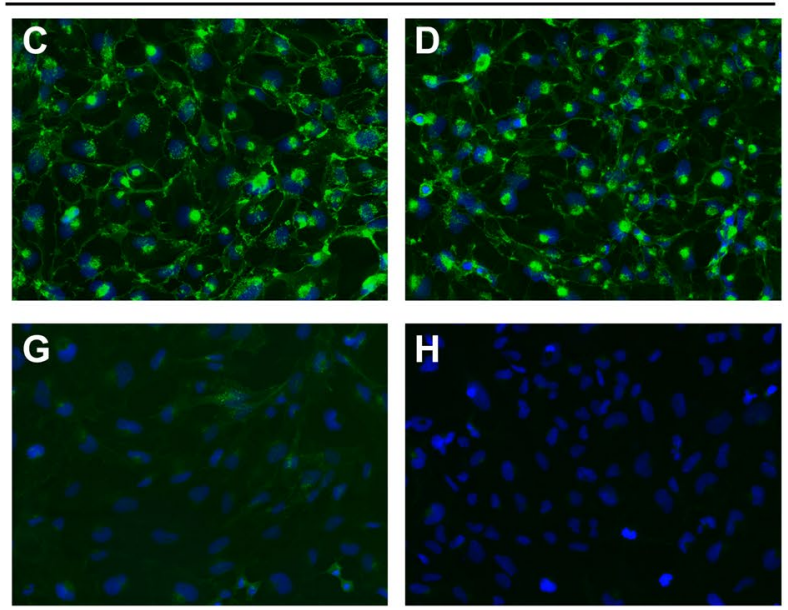

Figure 7. Interaction of Scedosporium apiospermum lectin SapL1 with bronchial epithelial cells. (A-D) Representative microscopic images of bronchial epithelial cells (BEAS-2B cell line) treated with SapL1-FITC (green) $\left(5(\mathrm{~A}, \mathrm{~B})\right.$ or $\left.10(\mathrm{C}, \mathrm{D}) \mu \mathrm{g} \mathrm{mL} \mathrm{m}^{-1}\right)$ for $1 \mathrm{~h}$. $(\mathbf{E}-\mathbf{H})$ Representative microscopic images of bronchial epithelial treated for $1 \mathrm{~h}$ with SapL1-FITC (green) $\left(5(\mathbf{E}, \mathbf{F})\right.$ or $\left.10(\mathbf{G}, \mathbf{H}) \mu \mathrm{g} \mathrm{mL}^{-1}\right)$ previously preincubated 30 min with $2 \mathrm{mM}$ methyl- $\alpha$-L-fucopyranoside ( $\mathrm{MMeFuc}$ ). Nuclei were labelled with 4'-6-diamidino-2-phenylindole dihydrochloride (DAPI, blue). Cells were visualized with an Olympus BX43 microscope (magnification $\times 20)$.

\section{Discussion}

In comparison with pathogenic bacteria, which have received particular attention for several years, there is a lack of information about the virulence factors and host recognition systems of pathogenic fungi ${ }^{38}$. This hinders the development of new drugs against these microorganisms, while their resistance to current antifungals is progressing quickly, $9,21,39$. Therefore, there is a rush in obtaining information that may contribute to the development of new antifungal agents.

In this study, we present the identification, production and characterization of a new carbohydrate-binding protein from the emerging microfungus $S$. apiospermum, whose host-anchoring mechanisms are completely unknown. To the best of our knowledge, this is the first studied lectin for this opportunistic pathogen. SapL1 is homologous to the conidial surface lectin FleA from A. fumigatus known to be involved in adhesion to the host glycoconjugates present in bronchial mucus and human lung epithelium ${ }^{28}$. When we analyzed the amino acid sequence deduced from SAPIO_CDS9261, we found at its N-terminus, a peptide sequence of 74 amino acids that was lacking in any other related protein. We believed in a possible error in the annotation of the open reading frame (ORF) of SapL1 since this peptide, predicted to be disordered, cannot be found in other protein and was not found in any other lectin from this family. We failed, however, to amplify the gene from total mRNAs from mycelium but recent transcriptomics data revealed that SapL1 is not usually expressed in mycelium apart in some conditions at low $\mathrm{pH}$ and in hypercapnia explaining our negative results ${ }^{40}$. By analogy to FleA, it is probably expressed in conidia and new amplification trials should be done on total mRNAs from conidia, but we did not have access to some at that time and there are no transcriptomic data available for this morphological stage to date. When looking at the transcript KEZ40204 for SAPIO_CDS9261, we noticed that the first exon containing the actual initial methionine is only 8 bases long followed by a very long intron of 686 bases which is quite unusual in fungi. After alignment of this transcript sequence from all genome sequences available for Scedosporium species, we saw that the proposed initial methionine is not conserved contrary to the one for Met75 (Fig. S6). Whilst waiting for experimental data, this strengthens our hypothesis for a gene misannotation and provides additional information that supports our decision to study the construct of SapL1 comprising only the predicted CRD.

In our initial attempts to produce recombinant SapL1, we observed that the conventional parameters of expression in E. coli, resulted in the production of insoluble protein that was mainly found in inclusion bodies. Later, experimental data indicated that the presence of rhamnose or glycerol was required for SapL1 solubilization during bacterial expression and that the production yield was directly proportional to their concentration in the culture medium. We initially considered that the higher production rates of SapL1 could be attributed to the dissociation of the LacI-DNA complex caused by an increase in cytosolic potassium concentration. The accumulation of this ion is one of the main adaptive responses of $E$. coli to hypertonic shocks and its concentration has been correlated to the loss of interactions between DNA and proteins in in vitro assays ${ }^{41-43}$. However, previous reports have demonstrated that, in vivo, the effects of macromolecular crowding caused by plasmolysis (the reduction of intracellular water content as an adaptive response to osmotic shock) on the activity of cytoplasmic proteins is sufficient to buffer the kinetics of association of DNA-protein against changes in $\left[\mathrm{K}^{+}\right]^{43,44}$. Thus, it seems that the higher recovery rates of SapL1 actually were caused by a combination of two main parameters: 1) the leak of genetic repression by dissociation of the LacI-DNA complex, that is characteristic of lac promoters and 2) a positive effect on the solubility and folding of the protein due to the increased concentration of organic osmoregulators, whose synthesis is induced in E. coli as an adaptive response to the external hypertonicity caused 
here by the addition of rhamnose to the culture medium ${ }^{41-49}$. This hypothesis was later supported by the finding that the addition of glycerol, instead of rhamnose, displays the same effect on production and solubility of SapL1 (data not shown). Plasmolysis may also play an essential role in SapL1 stabilization, since it has been shown that macromolecular crowding has positive effects on protein folding and in some cases it can drive self-association of improper folded proteins into functional oligomers ${ }^{43}$. These findings, and the extensive research carried out to produce SapL1 in its soluble form, provide important insights for the heterologous expression of eukaryotic lectins tending to be produced as insoluble proteins in E. coli. Besides, our findings highlight the useful role of organic osmoregulators during heterologous expression of proteins to favour their proper folding and to avoid the formation of inclusion bodies.

We demonstrated that SapL1 is strictly specific for fucosylated carbohydrates and recognized all blood group types present in the glycan array screening. These results are particularly interesting since it has been shown that there is six times more fucose $\alpha 1,3 / 4$ linked in glycoproteins in the CF airways ${ }^{31}$. This phenomenon is mainly due to an increased expression of the a1,3-fucosyltransferase, which is involved in the synthesis of sialyl-Lewis $\mathrm{X}$ and Lewis $\mathrm{X}$ determinants attached to bronchial mucins ${ }^{32}$. Therefore, the fact that SapL1 recognizes equally the $\alpha 1,2$ and $\alpha 1,3 / 4$-linked fucosides may explain the high incidence of scedosporiosis in CF patients. Besides, it correlates with the presence of SapL1 gene in all the pathogenic strains of Scedosporium whose genome has been sequenced to date ${ }^{33,50,51}$. However, there is no evidence suggesting that blood group phenotypes may have an influence in this recognition conversely to previous reports on other pathogens like Pseudomonas aeruginosa and Haemophilus influenzae $e^{52-54}$.

SapL1 adopts a the 6-bladed $\beta$-propeller fold and forms dimer leading to two fucose binding surfaces. It belongs to ProLec6A lectin family whose biological role is still unknown, in particular for the mushroom members ${ }^{35}$. The first member structurally characterized in this lectin family was AAL from the orange peel mushroom Aleuria aurantia ${ }^{55}$. It presents differences on both sides of the $\beta$-propeller with the microfungal members of this family: SapL1, AOL and FleA mainly at the level of the surface loops. On one side, this leads to a different dimerization interface and the dimer cannot overlay. On the other side, where sugar binding occurs, the differences in size and sequence of the surface loops lead to change in the architecture of the related binding sites and affect fucose binding since AAL has only five and not six functional binding sites ${ }^{27,37,55}$. The specificity and affinity of each one of the six binding pockets of SapL1 have been deeply analyzed to highlight the features that must be explored for the design of efficient inhibitors. Within our analysis, we found that the binding pockets are non-equivalent but they all share the features necessary for fucose recognition. This example of divergence can also be found in the other lectins of this family with FleA exhibiting the greatest differences between pockets known to date ${ }^{34}$. It is remarkable that although SapL1 has a relatively low sequence identity with other members of this family, its specificity and affinity are very similar to those reported for FleA from $A$. fumigatus $^{36}$, AAL from A. aurantia ${ }^{55}$ and the bacterial lectins BambL and RSL from Burkholderia ambifaria and Ralstonia solanacearum, respectively ${ }^{56,57}$.

Finally, fluorescence microscopy experiments allowed us to get preliminary results on SapL1 function. The lectin is able to recognize and to bind to bronchial epithelial cells, and we demonstrated that this binding is dependent on the recognition of fucosylated glycoconjugates at the surface of the target cells as it is abolished in the presence of fucose. These results corroborate a role of SapL1 in mediating the recognition and adhesion of S. apiospermum to host cells as found for other lectins from pathogenic microorganisms and in particular for its homolog FleA $^{22,27}$. Localisation of the lectin in the microfungus would also help to better understand its role but no SapL1 antibodies are yet available. Together with the crystallographic data, our study shows that the structure and function of lectins belonging to the 6-bladed $\beta$-propeller fucose specific family recently named PropLec6A are highly conserved, settling the possibility for development of a broad-spectrum therapy ${ }^{35}$.

Overall, our research has revealed the first insights about the recognition of fucosylated human glycoconjugates by S. apiospermum lectin SapL1 and contributes to the general understanding of the host-binding process during the early stages of infection. The lectin is found in all Scedosporium strains sequenced. The detailed information exposed here places SapL1 as a promising target for treatment of Scedosporium infections although it is clear that more functional data are still required. It will be of great value to guide the development of antiadhesive glycodrugs against this pathogen.

\section{Methods}

Production. The coding sequence for SapL1 (75-369) was optimized for expression in Escherichia coli and ordered at Eurofins Genomics (Ebersberg, Germany) before cloning into the expression vectors pET-TEV ${ }^{58}$, pET32-TEV 36 and pProNde. pProNde is a homemade vector where the NcoI restriction site of pProEx HTb (EMBL, Heidelberg) has been replaced by a NdeI restriction site by PCR. Then, plasmids were introduced into E. coli strains by thermal shock at $42^{\circ} \mathrm{C}$ and different expression parameters were assayed (Table S1) until soluble expression was achieved. Finally, SapL1 was expressed using pProNde vector in E. coli BL21trxB (DE3) strain with the cells grown at $37^{\circ} \mathrm{C}$ and $160 \mathrm{rpm}$ until an $\mathrm{OD}_{600}$ of 0.4 . The temperature was then lowered to $16^{\circ} \mathrm{C}$ and when $\mathrm{OD}_{600 \mathrm{~nm}}$ reached 0.8 , the induction was carried out overnight by the addition $0.05 \mathrm{mM}$ of IPTG and $1 \%$ L-rhamnose.

Purification. Cells were subsequently harvested by centrifugation at $5000 \mathrm{~g}$ for $10 \mathrm{~min}$ and resuspended in buffer A (50 mM Tris-HCl, $500 \mathrm{mM} \mathrm{NaCl}, \mathrm{pH}$ 8.5). After addition of $1 \mu \mathrm{L}$ of Denarase (C-LEcta GmbH, Leipzig, Germany) and moderate agitation during $30 \mathrm{~min}$ at room temperature, cells were disrupted at $1.9 \mathrm{kbar}$ using a cell disruptor (Constant Systems Ltd, UK). Cell debris were removed by centrifugation at 22,000 g for $30 \mathrm{~min}$. The supernatant was filtered using $0.45 \mu \mathrm{m}$ membranes (PES, ClearLine) and the protein purification was carried out by IMAC using $1 \mathrm{~mL}$ His-Trap FF columns (Cytiva) and a NGC chromatography system (Bio-Rad). 
After loading the supernatant, the column was rinsed thoroughly with buffer A until stabilization of the baseline. Bound proteins were eluted through the addition of buffer B $(50 \mathrm{mM}$ Tris- $\mathrm{HCl}, 500 \mathrm{mM} \mathrm{NaCl}, 500 \mathrm{mM}$ imidazole, pH 8.5) in an 0-500 mM imidazole gradient over $20 \mathrm{~mL}$. Fractions containing SapL1 were pooled and concentrated by ultrafiltration (Pall, $10 \mathrm{kDa}$ cut-off) prior buffer exchange to $50 \mathrm{mM}$ Tris- $\mathrm{HCl}, 100 \mathrm{mM} \mathrm{NaCl}$, $\mathrm{pH} 8.5$ using PD10 desalting columns (Cytiva). Then, the fusion was cleaved off overnight at $19^{\circ} \mathrm{C}$ using the TEV protease produced in the lab in 1:50 ratio and addition of $0.5 \mathrm{mM}$ EDTA and $0.25 \mathrm{mM}$ TCEP. The sample was loaded on the His-trap column to separate the cleaved protein collected in the flow-through from the TEV protease and potential uncleaved sample retained and eluted with imidazole. Sapll containing fractions were concentrated by centrifugation to the desired concentration.

Size exclusion chromatography. Size exclusion chromatography (SEC) was performed using a HighResolution ENrich SEC 70 column (Bio-Rad) on NGC chromatography system (Bio-Rad). Column was equilibrated with $50 \mathrm{~mL}$ of buffer D (20 mM MES, $100 \mathrm{mM} \mathrm{NaCl}, \mathrm{pH}$ 6.5) and $200 \mu \mathrm{L}$ of sample at $10 \mathrm{mg} \mathrm{mL}^{-1}$ were injected into the system followed by $40 \mathrm{~mL}$ isocratic elution on buffer $\mathrm{D}$ supplemented with $20 \mathrm{mM}$ a-methyl-Lfucoside (TCI Europe), $0.1 \%$ L-rhamnose, $5 \mathrm{M} \mathrm{NaCl}, 2 \mathrm{M} \mathrm{NaCl}$ or $500 \mathrm{mM} \mathrm{NaCl}$, according to the experiment. Fractions were monitored by the absorbance at $280 \mathrm{~nm}$ and $0.5 \mathrm{~mL}$ fractions were collected in the resolving region of the column.

Dynamic light scattering (DLS). DLS analyses were performed using a Zetasizer Nano ZS (Malvern Panalytical) with a $40 \mu \mathrm{l}$ quartz cuvette. Measurements were performed in triplicate on protein sample at $1 \mathrm{mg} \cdot \mathrm{mL}^{-1}$ in buffer $\mathrm{C}(50 \mathrm{mM}$ Tris- $\mathrm{HCl}, 100 \mathrm{mM} \mathrm{NaCl}, \mathrm{pH} 8.5)$ after centrifugation.

Thermal shift assay (TSA). The thermal stability of SapL1 was analyzed by TSA with the MiniOpticon real-time PCR system (Bio-Rad). Prior assay, buffer stocks at $100 \mathrm{mM}$ and a mixture containing $70 \mu \mathrm{L}$ of SapL1 at $1 \mathrm{mg} \mathrm{mL}-1,7 \mu \mathrm{L}$ of $500 \times$ Sypro Orange (Merk Sigma-Aldrich,) and $63 \mu \mathrm{L}$ of ultrapure $\mathrm{H}_{2} \mathrm{O}$ were prepared. Then, $7.5 \mu \mathrm{L}$ of $\mathrm{H}_{2} \mathrm{O}, 12.5 \mu \mathrm{L}$ of the corresponding buffer and $5 \mu \mathrm{L}$ of the protein/Sypro mixture were mixed in 96-well PCR microplates. The heat exchange test was then carried out from 20 to $100{ }^{\circ} \mathrm{C}$ with a heating rate of $1{ }^{\circ} \mathrm{C} \cdot \mathrm{min}^{-1}$. Fluorescence intensity was measured with $\mathrm{Ex} / \mathrm{Em}: 490 / 530 \mathrm{~nm}$ and the data processing was performed with the CFX Manager software.

Isothermal titration calorimetry (ITC). Experiments were performed using a Microcal ITC200 calorimeter (Malvern Panalytical) with $40 \mu \mathrm{L}$ of L-fucose $5 \mathrm{mM}$ in the syringe and $200 \mu \mathrm{L}$ of protein $0.05 \mathrm{mM}$ in the sample cell. Both, the protein and sugars were dissolved in a buffer composed of $20 \mathrm{mM}$ Tris $\mathrm{HCl} \mathrm{pH} 8.0$ and $100 \mathrm{mM} \mathrm{NaCl}$. A total of 26 injections of $1.5 \mu \mathrm{L}$ of ligand were added to the sample cell at intervals of $180 \mathrm{~s}$ while stirring at $850 \mathrm{rpm}$. Experimental data were adjusted to a theoretical titration curve by the Origin ITC Analysis software. All experiments were performed at least by duplicated and the stoichiometry was fixed to 1 .

Hemagglutination assay. Agglutination test was performed with fresh rabbit erythrocytes (bioMérieux, Lyon) in U 96-well plates (Nalgene). For the test, $150 \mathrm{mM} \mathrm{NaCl}$ was used as a negative control and $1 \mathrm{mg} \mathrm{mL}^{-1}$. LecB of $P$. aeruginosa as a positive control. $50 \mu \mathrm{L}$ of sample was prepared at $0.1 \mathrm{mg} \cdot \mathrm{mL}^{-1}$ and submitted to serial double dilutions. $50 \mu \mathrm{L}$ of rabbit erythrocytes $3 \%$ were added to each well prior incubation of the plate at room temperature. After $2 \mathrm{~h}$, the result of the experiment was evaluated and agglutination activity was calculated according to the dilution of the protein.

Glycan arrays. Protein was labelled with Fluorescein Isothiocyanate (FITC, Merk, Sigma-Aldrich) according to the supplier's instructions with slight modifications. Briefly two milligrams of protein were dissolved in $1 \mathrm{~mL}$ of buffer $\mathrm{E}\left(100 \mathrm{mM} \mathrm{Na}_{2} \mathrm{CO}_{3}, 100 \mathrm{mM} \mathrm{NaCl}, \mathrm{pH}\right.$ 9); then, $40 \mu \mathrm{L}$ of FITC at $1 \mathrm{mg} \cdot \mathrm{mL}^{-1}$, previously dissolved in DMSO, were gradually added to the protein solution and the mixture was gently stirred at room temperature overnight. Next day, the solution was supplemented with $\mathrm{NH}_{4} \mathrm{Cl}$ to a final concentration of $50 \mathrm{mM}$ and free FITC was removed using PD10 column with PBS as mobile phase. Protein concentration was determined at $A_{280}$ and FITC at $A_{490}$ using a NanoDrop 200 (Thermo Scientific) and Fluorescein/Protein molar ratio (F/P) was estimated by the following formula:

$$
\operatorname{Molar} \frac{\mathrm{F}}{\mathrm{P}}=\frac{\mathrm{MW}}{389} \times \frac{\frac{A_{495}}{195}}{\left[A_{280}-\left(0.35 \times A_{495}\right)\right] E^{0.1 \%}}
$$

where MW is the molecular weight of the protein, 389 is the molecular weight of FITC, 195 is the absorption E $0.1 \%$ of bound FITC at $490 \mathrm{~nm}$ at pH 13.0, (0.35 X A495) is the correction factor due to the absorbance of FITC at $280 \mathrm{~nm}$, and $\mathrm{E} 0.1 \%$ is the absorption at $280 \mathrm{~nm}$ of a protein at $1.0 \mathrm{mg} \cdot \mathrm{mL}^{-1}$. Being an ideal $\mathrm{F} / \mathrm{P}$ should be $0.3>1$.

Labelled lectin was sent to the Consortium for Functional Glycomics (CFG; Boston, MA, USA) and its binding properties were assayed at 5 and $50 \mu \mathrm{g} \cdot \mathrm{mL}^{-1}$ on a "Mammalian Glycan Array version 5.4" which contain 585 glycans in replicates of 6 . The highest and lowest signal of each set of replicates were eliminated and the average of the remaining data was normalized to the percentages of the highest RFU value for each analysis. Finally, the percentages for each glycan were averaged at different lectin concentrations.

Crystallization and data collection. Crystal screening was performed using the hanging-drop vapour diffusion technique by mixing equal volumes of pure protein at $5 \mathrm{mg} \cdot \mathrm{mL}^{-1}$ and precipitant solutions from com- 
mercial screenings of Molecular Dimensions (Newmarket, UK). $2 \mu \mathrm{L}$ drops were incubated at $19^{\circ} \mathrm{C}$ until crystals appeared. A subsequent optimization of positive conditions for SapL1 crystallization was carried out and crystals suitable for X-ray diffraction analysis were obtained under solution containing $100 \mathrm{mM}$ Bicine pH 8.5, $1.5 \mathrm{M}$ ammonium sulfate $\left(\mathrm{NH}_{4}\right)_{2} \mathrm{SO}_{4}$ and $12 \% \mathrm{v} / \mathrm{v}$ glycerol. Crystals were soaked in mother liquor supplemented with $10 \%(\mathrm{v} / \mathrm{v})$ glycerol, prior to flash cooling in liquid nitrogen. Data collection was performed on PX1 beamline at SOLEIL Synchrotron (Saint Aubin, France) using an Eiger2 X 9M pixel detector (Dectris Ltd, Switzerland).

Structure determination. Data were processed using $\mathrm{XDS}^{59}$ software and were converted to structure factors using the CCP4 program package v. $6.1^{60}$, with $5 \%$ of the data reserved for Rfree calculation. The structure was determined using the molecular-replacement method with Phaser v.2.5 $5^{61}$, using the structure of FleA dimer (PDB entry $4 \mathrm{D} 4 \mathrm{U}^{34}$ ) as starting model. Model refinement was performed using REFMAC $5.8^{62}$ alternated with manual model building in Coot v.0.763. Sugar residues and other compounds that were present were placed manually using Coot and validated using Privateer ${ }^{64}$. The final model has been validated and deposited in the PDB Database with accession number 6TRV.

Cell culture and fluorescence microscopy. Human bronchial epithelial cells (BEAS-2B cell line) were maintained and serially passaged in F-12 culture medium supplemented with 10\% fetal calf serum (FCS), $1 \%$ penicillin and streptomycin, and $10 \mathrm{mM}$ HEPES in $75-\mathrm{cm}^{2}$ culture flasks. For microscopy experiments, BEAS2B cells were grown to confluency on coverslips (precision cover glasses thickness No. 1.5H; Marienfeld, LaudaKönigshofen, Germany). To test interaction of SapL1 lectin with epithelial cells, BEAS-2B cells were incubated with different concentrations of FITC-lectin $\left(5\right.$ or $10 \mu \mathrm{g} \mathrm{mL}^{-1}$ in F-12) for $1 \mathrm{~h}$ at $37^{\circ} \mathrm{C}$. To validate the specificity of this interaction, SapL1-FITC was co-incubated in presence of $2 \mathrm{mM}$ methyl- $\alpha$-L-fucopyranoside for $30 \mathrm{~min}$ at $37^{\circ} \mathrm{C}$ and then added to the cells for $1 \mathrm{~h}$. Supernatant was then removed, cells washed 3 times with F-12, once with PBS and then fixed with $4 \%$ paraformaldehyde for $15 \mathrm{~min}$. After 3 washes with PBS, nuclei were stained with 4'-6-diamidino-2-phenylindole dihydrochloride (DAPI, 1:1000 in PBS) for $5 \mathrm{~min}$. Coverslip were mounted with Prolong Glass Antifade Mountant (Invitrogen) on Superfrost glass slides (Thermo Fisher Scientific). Images were acquired with an upright Olympus BX43 microscope.

Figures were created using PyMOL Version 1.8.4 (Schrödinger), ChemDraw Version 15, ESPript Version $3.0^{65}$ and PowerPoint 16.

\section{Accession numbers}

The structure of SapL1 was deposited as PDB ID: 6TRV.

Received: 17 December 2020; Accepted: 16 July 2021

Published online: 09 August 2021

\section{References}

1. Tuite, N. L. \& Lacey, K. Vol. 968 (eds Louise O’Connor \& Barry Glynn) 1-23 (Humana Press, Totowa, NJ, 2013).

2. Thornton, C. R. Detection of the "Big Five" mold killers of humans: Aspergillus, Fusarium, Lomentospora, Scedosporium and Mucormycetes. Adv. Appl. Microbiol. 110, 1-61. https://doi.org/10.1016/bs.aambs.2019.10.003 (2020).

3. Gilgado, F., Cano, J., Gené, J. \& Guarro, J. Molecular phylogeny of the Pseudallescheria boydii species complex: proposal of two new species. J. Clin. Microbiol. 43, 4930-4942. https://doi.org/10.1128/JCM.43.10.4930-4942.2005 (2005).

4. Ramirez-Garcia, A. et al. Scedosporium and Lomentospora: an updated overview of underrated opportunists. Med. Mycol. 56, S102-S125. https://doi.org/10.1093/mmy/myx113 (2018).

5. Bouchara, J.-P. et al. Advances in understanding and managing Scedosporium respiratory infections in patients with cystic fibrosis. Expert Rev. Respir. Med. 14, 259-273. https://doi.org/10.1080/17476348.2020.1705787 (2020).

6. Rammaert, B. et al. Perspectives on Scedosporium species and Lomentospora prolificans in lung transplantation: results of an international practice survey from ESCMID fungal infection study group and study group for infections in compromised hosts, and European Confederation of Medical Mycology. Transpl. Infect. Dis. 21, 1-8. https://doi.org/10.1111/tid.13141 (2019).

7. Luplertlop, N. Pseudallescheria/Scedosporium complex species: from saprobic to pathogenic fungus. J. Mycol. Med. 28, $249-256$. https://doi.org/10.1016/j.mycmed.2018.02.015 (2018).

8. Tortorano, A. M. et al. ESCMID and ECMM joint guidelines on diagnosis and management of hyalohyphomycosis: Fusarium spp., Scedosporium spp. and others. Clin. Microbiol. Infect. 20, 27-46. https://doi.org/10.1111/1469-0691.12465 (2014).

9. Guarro, J. et al. Scedosporium apiospermum: changing clinical spectrum of a therapy-refractory opportunist. Med. Mycol. 44, 295-327. https://doi.org/10.1080/13693780600752507 (2006).

10. Troke, P. et al. Treatment of scedosporiosis with voriconazole: clinical experience with 107 patients. Antimicrob. Agents Chemother. 52, 1743-1750. https://doi.org/10.1128/AAC.01388-07 (2008).

11. Cortez, K. J. et al. Infections caused by Scedosporium spp. Clin. Microbiol. Rev. 21, 157-197. https://doi.org/10.1128/CMR.00039-07 (2008).

12. Theuretzbacher, U. \& Piddock, L. J. V. Non-traditional antibacterial therapeutic options and challenges. Cell Host Microbe 26, 61-72. https://doi.org/10.1016/j.chom.2019.06.004 (2019).

13. Krachler, A. M. \& Orth, K. Targeting the bacteria-host interface strategies in anti-adhesion therapy. Virulence 4, 284-294. https:// doi.org/10.4161/viru.24606 (2013).

14. Ofek, I., Hasty, D. L. \& Sharon, N. Anti-adhesion therapy of bacterial diseases: prospects and problems. FEMS Immunol. Med. Microbiol. 38, 181-191. https://doi.org/10.1016/S0928-8244(03)00228-1 (2003).

15. Figueiredo, R. T. et al. TLR4 recognizes Pseudallescheria boydii conidia and purified rhamnomannans. J. Biol. Chem. 285, 4071440723. https://doi.org/10.1074/jbc.M110.181255 (2010)

16. Pinto, M. R., Gorin, P. A. J., Wait, R., Mulloy, B. \& Barreto-Bergter, E. Structures of the O-linked oligosaccharides of a complex glycoconjugate from Pseudallescheria boydii. Glycobiology 15, 895-904. https://doi.org/10.1093/glycob/cwi084 (2005).

17. Pinto, M. R. et al. Involvement of peptidorhamnomannan in the interaction of Pseudallescheria boydii and HEp2 cells. Microbes Infect. 6, 1259-1267. https://doi.org/10.1016/j.micinf.2004.07.006 (2004).

18. Bittencourt, V. C. B. et al. An a-glucan of Pseudallescheria boydii is involved in fungal phagocytosis and Toll-like receptor activation. J. Biol. Chem. 281, 22614-22623. https://doi.org/10.1074/jbc.M511417200 (2006). 
19. Ghamrawi, S. et al. Cell wall modifications during conidial maturation of the human pathogenic fungus Pseudallescheria boydii. PLoS ONE 9, e100290. https://doi.org/10.1371/journal.pone.0100290 (2014).

20. Rollin-Pinheiro, R., Liporagi-lopes, L. C., Meirelles, J. V. D. \& Souza, L. M. D. Characterization of Scedosporium apiospermum glucosylceramides and their involvement in fungal development and macrophage functions. PLoS ONE 9, e98149. https://doi.org/ 10.1371/journal.pone.0098149 (2014).

21. De Mello, T. P. et al. Scedosporium apiospermum, Scedosporium aurantiacum, Scedosporium minutisporum and Lomentospora prolificans: a comparative study of surface molecules produced by conidial and germinated conidial cells. Mem. Inst. Oswaldo Cruz 113, 1-8. https://doi.org/10.1590/0074-02760180102 (2018).

22. Imberty, A. \& Varrot, A. Microbial recognition of human cell surface glycoconjugates. Curr. Opin. Struct. Biol. 18, 567-576. https:// doi.org/10.1016/j.sbi.2008.08.001 (2008).

23. Sharon, N. Carbohydrates as future anti-adhesion drugs for infectious diseases. Biochim. Biophys. Acta 1760, 527-537. https://doi. org/10.1016/j.bbagen.2005.12.008 (2006).

24. Tamburrini, A., Colombo, C. \& Bernardi, A. Design and synthesis of glycomimetics: recent advances. Med. Res. Rev. 40, 495-531. https://doi.org/10.1002/med.21625 (2020).

25. Sattin, S. \& Bernardi, A. Glycoconjugates and glycomimetics as microbial anti-adhesives. Trends Biotechnol. 34, 483-495. https:// doi.org/10.1016/j.tibtech.2016.01.004 (2016).

26. Pieters, R. J. Carbohydrate mediated bacterial adhesion. Adv. Exp. Med. Biol. 715, 227-240. https://doi.org/10.1007/978-94-0070940-9_14 (2011).

27. Houser, J. et al. A soluble fucose-specific lectin from Aspergillus fumigatus conidia: structure, specificity and possible role in fungal pathogenicity. PLoS ONE 8, e83077. https://doi.org/10.1371/journal.pone.0083077 (2013).

28. Kerr, S. C. et al. FleA expression in Aspergillus fumigatus is recognized by fucosylated structures on mucins and macrophages to prevent lung infection. PLOS Pathog. 12, e100555. https://doi.org/10.1371/journal.ppat.1005555 (2016).

29. Sakai, K., Hiemori, K., Tateno, H., Hirabayashi, J. \& Gonoi, T. Fucose-specific lectin of Aspergillus fumigatus: binding properties and effects on immune response stimulation. Med. Mycol. 57, 71-83. https://doi.org/10.1093/mmy/myx163 (2019).

30. Thornton, D. J., Rousseau, K. \& McGuckin, M. A. Structure and function of the polymeric mucins in airways mucus. Annu. Rev. Physiol. 70, 459-486. https://doi.org/10.1146/annurev.physiol.70.113006.100702 (2008).

31. Glick, M. C., Kothari, V. A., Liu, A., Stoykova, L. I. \& Scanlin, T. F. Activity of fucosyltransferases and altered glycosylation in cystic fibrosis airway epithelial cells. Biochimie 83, 743-747. https://doi.org/10.1016/s0300-9084(01)01323-2 (2001).

32. Lamblin, G. et al. Human airway mucin glycosylation: a combinatory of carbohydrate determinants which vary in cystic fibrosis. Glycoconj. J. 18, 661-684. https://doi.org/10.1023/A:1020867221861 (2001).

33. Vandeputte, P. et al. Draft genome sequence of the pathogenic fungus Scedosporium apiospermum. Genome Announc. 2, e00988-e914. https://doi.org/10.1128/genomea.00988-14 (2014).

34. Houser, J. et al. Structural insights into Aspergillus fumigatus lectin specificity: AFL binding sites are functionally non-equivalent. Acta Crystallogr. D Biol. Crystallogr. https://doi.org/10.1107/S1399004714026595 (2015).

35. Bonnardel, F. et al. Architecture and evolution of blade assembly in $\beta$-propeller lectins. Structure 27, 764-775.e763. https://doi. org/10.1016/j.str.2019.02.002 (2019).

36. Lehot, V. et al. Multivalent fucosides with nanomolar affinity for the Aspergillus fumigatus lectin FleA prevent spore adhesion to pneumocytes. Chem. Eur. J. 24, 19243-19249. https://doi.org/10.1002/chem.201803602 (2018).

37. Makyio, H. et al. Six independent fucose-binding sites in the crystal structure of Aspergillus oryzae lectin. Biochem. Biophys. Res. Commun. 477, 477-482. https://doi.org/10.1016/j.bbrc.2016.06.069 (2016).

38. Hogan, L. H., Klein, B. S. \& Levitz, S. M. Virulence factors of medically important fungi. Clin. Microbiol. Rev. 9, 469-488. https:// doi.org/10.1128/CMR.9.4.469-488.1996 (1996).

39. Debourgogne, A., Dorin, J. \& Machouart, M. Emerging infections due to filamentous fungi in humans and animals: only the tip of the iceberg?. Environ. Microbiol. Rep. 8, 332-342. https://doi.org/10.1111/1758-2229.12404 (2016).

40. Vandeputte, P. et al. Comparative transcriptome analysis unveils the adaptative mechanisms of Scedosporium apiospermum to the microenvironment encountered in the lungs of patients with cystic fibrosis. Comput. Struct. Biotechnol. J. 18, 3468-3483. https:// doi.org/10.1016/j.csbj.2020.10.034 (2020).

41. Frank, D. E. et al. Thermodynamics of the interactions of Lac repressor with variants of the symmetric Lac operator: effects of converting a consensus site to a non-specific site. J. Mol. Biol. 267, 1186-1206. https://doi.org/10.1006/jmbi.1997.0920 (1997).

42. Capp, M. W. et al. Compensating effects of opposing changes in putrescine (2+) and $\mathrm{K}+$ concentrations on lac repressor-lac operator binding: in vitro thermodynamic analysis and in vivo relevance. J. Mol. Biol. 258, 25-36. https://doi.org/10.1006/jmbi.1996.0231 (1996).

43. Cayley, S., Lewis, B. A., Guttman, H. J. \& Record, M. T. Characterization of the cytoplasm of Escherichia coli K-12 as a function of external osmolarity implications for protein-DNA interactions in vivo. J. Mol. Biol. 222, 281-300. https://doi.org/10.1016/00222836(91)90212-o (1991).

44. Richeys, B. et al. Variability of the intracellular ionic environment of Escherichia coli differences between in vitro and in vivo effects of ion concentrations on protein-DNA interactions and gene expression. J. Biol. Chem. 262, 7157-7164 (1987)

45. Harries, D., Rosgen, J. Vol. 84 679-735 (Elsevier, 2008).

46. Massiah, M. A., Wright, K. M. \& Du, H. Obtaining soluble folded proteins from inclusion bodies using sarkosyl, Triton X-100, and CHAPS: application to LB and M9 minimal media. Curr. Protoc. Protein Sci. 84, 1-24. https://doi.org/10.1002/0471140864. ps0613s84 (2016).

47. Pettitt, B. M. \& Bolen, D. W. Protein folding, stability, and solvation structure in osmolyte solutions. Biophys. J. 89, 2988-2997. https://doi.org/10.1529/biophysj.105.067330 (2005).

48. Singh, L. R. et al. Forty years of research on osmolyte-induced protein folding and stability. J. Iran. Chem. Soc. 8, 1-23 (2011).

49. Ajito, S., Iwase, H., Takata, S.-I. \& Hirai, M. Sugar-mediated stabilization of protein against chemical or thermal denaturation. J. Phys. Chem. B 122, 8685-8697. https://doi.org/10.1021/acs.jpcb.8b06572 (2018).

50. Pérez-Bercoff, Å. et al. Draft genome of Australian environmental strain WM 09.24 of the opportunistic human pathogen Scedosporium aurantiacum. Genome Announc. 3, e01526-01514, doi:https://doi.org/10.1128/genomeA.01526-14 (2015).

51. Duvaux, L. et al. Draft genome sequence of the human-pathogenic fungus Scedosporium boydii. Genome Announc. 5, e00871-e817. https://doi.org/10.1128/genomeA.00871-17 (2017).

52. Kuo, K. C., Kuo, H. C., Huang, L. T., Lin, C. S. \& Yang, S. N. The clinical implications of ABO blood groups in Pseudomonas aeruginosas sepsis in children. J. Microbiol. Immunol. Infect. 46, 109-114. https://doi.org/10.1016/j.jmii.2012.01.003 (2013).

53. Scanlin, T. F. \& Glick, M. C. Terminal glycosylation in cystic fibrosis. Biochim. Biophys. Acta 1455, 241-253. https://doi.org/10. 1016/S0925-4439(99)00059-9 (1999).

54. Taylor-Cousar, J. L. et al. Histo-blood group gene polymorphisms as potential genetic modifiers of infection and cystic fibrosis lung disease severity. PLoS ONE 4, e4270. https://doi.org/10.1371/journal.pone.0004270 (2009).

55. Wimmerova, M., Mitchell, E., Sanchez, J. F., Gautier, C. \& Imberty, A. Crystal structure of fungal lectin: six-bladed $\beta$-propeller fold and novel fucose recognition mode for Aleuria aurantia lectin. J. Biol. Chem. 278, 27059-27067. https://doi.org/10.1074/jbc. M302642200 (2003).

56. Audfray, A. et al. Fucose-binding lectin from opportunistic pathogen Burkholderia ambifaria binds to both plant and human oligosaccharidic epitopes. J. Biol. Chem. 287, 4335-4347. https://doi.org/10.1074/jbc.M111.314831 (2012). 
57. Kostlanova, N. et al. The fucose-binding lectin from Ralstonia solanacearum: a new type of $\beta$-propeller architecture formed by oligomerization and interacting with fucoside, fucosyllactose, and plant xyloglucan. J. Biol. Chem. 280, 27839-27849. https://doi. org/10.1074/jbc.M505184200 (2005).

58. Houben, K., Marion, D., Tarbouriech, N., Ruigrok, R. W. H. \& Blanchard, L. Interaction of the C-terminal domains of sendai virus $\mathrm{N}$ and P proteins: comparison of polymerase-nucleocapsid interactions within the paramyxovirus family. J. Virol. 81, 6807-6816. https://doi.org/10.1128/jvi.00338-07 (2007).

59. Kabsch, W. XDS. Acta Crystallogr. D Biol. Crystallogr. 66, 125-132, doi:https://doi.org/10.1107/S0907444909047337 (2010).

60. Winn, M. D. et al. Overview of the CCP4 suite and current developments. Acta Crystallogr. D Biol. Crystallogr. 67, 235-242. https:// doi.org/10.1107/S0907444910045749 (2011).

61. McCoy, A. J. et al. Phaser crystallographic software. J. Appl. Cryst. 40, 658-674. https://doi.org/10.1107/S0021889807021206 (2007).

62. Murshudov, G. N. \& Nicholls, R. A. REFMAC 5 for the refinement of macromolecular crystal structures. Acta Crystallogr. D Biol. Crystallogr. 67, 355-367. https://doi.org/10.1107/S0907444911001314 (2011).

63. Emsley, P. \& Lohkamp, B. Features and development of Coot. Acta Crystallogr. D Biol. Crystallogr. 66, 486-501. https://doi.org/10. 1107/S0907444910007493 (2010).

64. Aguirre, J. et al. Privateer: software for the conformational validation of carbohydrate structures. Nat. Struct. Mol. Biol. 22, 833-834. https://doi.org/10.1038/nsmb.3115 (2015).

65. Robert, X. \& Gouet, P. Deciphering key features in protein structures with the new ENDscript server. Nucleic Acids Res. 42, 320-324. https://doi.org/10.1093/nar/gku316 (2014).

\section{Acknowledgements}

We would like to thank to Valérie Chazalet and Emilie Gillon for their technical assistance. We are grateful to the Consortium for Functional Glycomics for providing the glycan array resource. We also would like to thank for access to the beamlines BM30A-FIP at the European Synchrotron Radiation Facility (ESRF), Grenoble, France where initial tests were performed and Proxima 1 at SOLEIL Synchrotron, Saint Aubin, France (Proposal Number 20170827), where final data were collected. Thanks to our local contacts Jean-Luc Ferrer, Serena Sirigu, and Pierre Legrand for their assistance and technical support.

\section{Author contributions}

D.M.A. performed cloning, protein expression, protein purification, protein labelling, hemaglutination, isothermal microcalorimetry measurements. V.B. performed the fluorescence microscopy experiments. D.M.A. participated in all steps of protein crystallography and data analysis, wrote the original draft of the manuscript and prepared all figures. J-P.B. provided the genome data for the bioinformatics studies and contributed to revise the manuscript. R.J.P. participated in the supervision of D.M.A, funding acquisition and revision of the manuscript. A.V. administered the project, conceived the design of the study, obtained funding, evaluated the results, contributed to data analysis, supervised D.M.A., helps in the preparation of the manuscript and contributed to revise the manuscript and the figures. All authors have read and agreed to the published version of the manuscript.

\section{Funding}

This project has received funding from the European Union's Horizon 2020 research and innovation program under the Marie Skłodowska-Curie grant (H2020-MSCA-ITN-2017-EJD-765581), from the French cystic fibrosis association Vaincre la Mucoviscidose. The project was also supported by Glyco@Alps (ANR-15-IDEX02).

\section{Competing interests}

The authors declare no competing interests.

\section{Additional information}

Supplementary Information The online version contains supplementary material available at https://doi.org/ 10.1038/s41598-021-95008-4.

Correspondence and requests for materials should be addressed to A.V.

Reprints and permissions information is available at www.nature.com/reprints.

Publisher's note Springer Nature remains neutral with regard to jurisdictional claims in published maps and institutional affiliations.

Open Access This article is licensed under a Creative Commons Attribution 4.0 International License, which permits use, sharing, adaptation, distribution and reproduction in any medium or format, as long as you give appropriate credit to the original author(s) and the source, provide a link to the Creative Commons licence, and indicate if changes were made. The images or other third party material in this article are included in the article's Creative Commons licence, unless indicated otherwise in a credit line to the material. If material is not included in the article's Creative Commons licence and your intended use is not permitted by statutory regulation or exceeds the permitted use, you will need to obtain permission directly from the copyright holder. To view a copy of this licence, visit http://creativecommons.org/licenses/by/4.0/.

(C) The Author(s) 2021 